\title{
Benign Sternal Neoplasm
}

National Cancer Institute

\section{Source}

National Cancer Institute. Benign Sternal Neoplasm. NCI Thesaurus. Code C8416.

A rare non-metastasizing neoplasm that arises from the sternum. 